\title{
Spatial Pattern Analysis of a Water-Related Ecosystem Service and Evaluation of the Grassland-Carrying Capacity of the Heihe River Basin under Land Use Change
}

\author{
Rui Luo ${ }^{1,+} \oplus$, Shiliang Yang ${ }^{2,+} \oplus$, Yang Zhou ${ }^{2, *}$, Pengqun Gao ${ }^{2}$ and Tianming Zhang ${ }^{2}$ \\ 1 First Surveying and Mapping Institute, Department of Natural Resources of Guizhou Province, \\ Guiyang 550002, China; lauyyn@126.com \\ 2 Business School, Hohai University, Nanjing 210000, China; max388@126.com (S.Y.); pqgao@hhu.edu.cn (P.G.); \\ zhangtianming1016@126.com (T.Z.) \\ * Correspondence: zhouyang1984823@hhu.edu.cn \\ + Rui Luo and Shiliang Yang contributed equally to this paper. Therefore, Rui Luo and Shiliang Yang are all the \\ first authors of this article.
}

check for

updates

Citation: Luo, R.; Yang, S.; Zhou, Y.; Gao, P.; Zhang, T. Spatial Pattern Analysis of a Water-Related

Ecosystem Service and Evaluation of the Grassland-Carrying Capacity of the Heihe River Basin under Land Use Change. Water 2021, 13, 2658. https://doi.org/10.3390/w13192658

Academic Editors: Fan-Rui Meng and Junyu Qi

Received: 12 August 2021

Accepted: 23 September 2021

Published: 26 September 2021

Publisher's Note: MDPI stays neutral with regard to jurisdictional claims in published maps and institutional affiliations.

Copyright: (c) 2021 by the authors. Licensee MDPI, Basel, Switzerland. This article is an open access article distributed under the terms and conditions of the Creative Commons Attribution (CC BY) license (https:// creativecommons.org/licenses/by/ $4.0 /)$.

\begin{abstract}
A key challenge to the sustainability and security of grassland capacity is the protection of water-related ecosystem services (WESs). With the change of land use, the supply of aquatic ecosystem services has changed, and the grassland-carrying capacity has been affected. However, the correlation mechanism between WESs and the grassland-carrying capacity is not clear. In this study, we used the InVEST (Integrated Valuation of Ecosystem Services and Tradeoffs) model to evaluate the impact of land-use change on WESs, and made a tradeoff analysis between WESs and grassland-carrying capacity. Considering that the Heihe River Basin (HRB) was an important grassland vegetation zone, which was a milestone for the development of animal husbandry in China, HRB was taken as a case. The main findings are as follows: (1) the spatial distribution of WESs shows the dissimilation rule, the upper reaches are the main water yield area, the soil retention is weakening in the middle and lower reaches, and the pollution has further increased in the middle and upper reaches. (2) The carrying capacity of animal husbandry decreased in the upper reaches, increased in Shandan County and Zhangye City in the middle reaches, and decreased sharply in other regions. (3) There was a positive correlation between the livestock-carrying capacity and nitrogen export in 2018, which was increasing. As the change of land use has changed the evapotranspiration structure, WESs have undergone irreversible changes. Meanwhile, the development of large-scale irrigated farmland and human activities would be the source of a further intensification of regional soil erosion and water pollution. Therefore, it is necessary to trade off the WESs and animal husbandry under land-use change. This paper revealed how WESs changed from 2000 to 2018, the characteristics of the changes in the spatial and temporal distribution, and the carrying capacity. It aims to provide a scientific basis for coordinating the contradiction between grassland and livestock resources, improving the regional ecological security situation, and carrying out ecosystem management.
\end{abstract}

Keywords: water-related ecosystem services; stocking capacity; land-use/cover change; InVEST; tradeoff

\section{Introduction}

In the context of global change, with the rapid development of the economy and society, most of the Earth's Ecosystem Services have experienced a decreasing trend, primarily due to the increasing human dominance in the natural environment [1-3]. Internationally, from a watershed to a global scale, the changes of WESs caused by land-use and landcover change (LUCC) have attracted much attention. Land-use change leads to land-cover change, which has important impacts on hydrological processes and water ecology [4-6]. The process of land-use change is closely related to the level of ecological environment security, and unreasonable land-use patterns often become the inducing factors that threaten 
regional ecological security [7]. Land conversion thus results in a negative externality, mediated by changes in biodiversity [8].

The impact of land-use change on aquatic ecosystem services will lead to the change of the grassland-carrying capacity. At present, many types of research have been done on how to improve the carrying capacity of grassland and the healthy development of animal husbandry [9-16]. These studies reveal several problems in the assessment of ecological services and carrying capacity. The first problem is how to quantitatively and scientifically evaluate WESs. The second is limited to the correlation analysis of the grassland area and livestock-carrying capacity, and the restriction of livestock quantity, which is onesided, is not considered enough. Third, the existing ecological grassland protection and carrying capacity policy are not refined enough. Therefore, it is difficult to reveal the spatial differences and the management of the carrying capacity under ecological constraints, which lacks practical guidance for ecological construction and protection.

The ecological environment of arid inland river basins is worsening in northwest China, including the case of HRB [17], concentrated in the lower reaches of the river basin, where forest vegetation and grassland vegetation have fallen sharply, soil erosion has increased, livestock overload has intensified, land desertification has increased, and pollution problems have become prominent. Such a common feature of the deterioration of the ecological environment has always been the focus of attention [18]. The stable development of the economy and society in arid regions has become a key factor in determining the construction of an ecological civilization and the high-quality development of the region [19]. Located in the middle of the Hexi Corridor, HRB, which spans three provinces and the autonomous regions of Qinghai, Gansu, and Inner Mongolia, is the largest inland river basin in Hexi and the most representative watershed in the arid region of Northwest China. It includes the Qilian Mountains and other national ecological reserves. It is an important ecological barrier and an important economic zone for the protection of the Yellow River, in China. In the past, the research on HRB mainly focused on: land-use change [20,21], assessment of land-use change on ecological service value [14], the impact of cultivated land and residential land change on the ecological environment [22], impact of human activities on the water environment [23], control process of the distribution of water resources on the landscape pattern [24], human-intensive management and transformation of the landscape [25], characteristics and tendencies of annual runoff variations [26], sensitivity and resilience of the ecosystem to climate variability [12], grazing capacity [27], waterecosystem-economy nexus [28]. Due to HRB's important strategic position, maintaining sustainable ecosystem services and healthy animal husbandry can play a supporting role in its economic and social development. From the above, there is a gap in the tradeoff and evaluation of the grassland livestock-carrying capacity and WESs. Therefore, the ecological protection and restoration of HRB have risen to the national ecological security strategy, which is a new pattern in building an ecological civilization and shaping coordinated regional development.

This research ultimately involves the following scientific objectives: (1) to accurately describe the spatiotemporal variability of WESs by the InVEST model; (2) to quantitatively analyze the grassland-carrying capacity under ecological constraints; (3) to trade off the relationship between the livestock-carrying capacity and WESs. The InVEST model was jointly developed in 2007 by Stanford University, the Nature Conservation Association (TNC), and the World Wide Fund for Nature (WWF). This model can quantitatively evaluate various ecological services and reflect their spatial distribution characteristics, providing a scientific basis for natural resource management decisions [29-32]. At the same time, the model could be used to judge the positive and negative impacts of different policies on ecosystems and was also a practical, low-cost approach to quantifying ecosystem services $[33,34]$. Based on this, this paper uses the internationally recognized InVEST model to quantitatively analyze the water yield, soil retention and erosion, and nitrogen and phosphorus export in HRB, and to find out the main factors and regions that cause ecological degradation. Meanwhile, the methods of RS, GIS, and quantitative 
statistical analysis are used to calculate the grassland-carrying capacity and to achieve precise management and control.

\section{Materials and Methods}

\subsection{Study Area}

HRB is the second-largest inland river basin in the arid area of northwest China, which is located in the middle of Qilian Mountain and the Hexi Corridor $\left(96^{\circ} 42^{\prime} \mathrm{E}-102^{\circ} 00^{\prime} \mathrm{E}\right.$, $37^{\circ} 41^{\prime} \mathrm{E}-42^{\circ} 42^{\prime} \mathrm{E}$ )) (Figure 1). The total length of the main stream is $821 \mathrm{~km}$, and the total area of the basin is $12.8 \times 10^{4} \mathrm{~km}^{2}$. The annual average temperature is $-3 \sim 7^{\circ} \mathrm{C}$, the annual precipitation is $37.29 \sim 680.25 \mathrm{~mm}$, and the annual evaporation is $151.61 \sim 1294.70 \mathrm{~mm}$. The altitude distribution of HRB shows a decreasing trend from south to north, with the lowest altitude of $716 \mathrm{~m}$ and the highest altitude of $5583 \mathrm{~m}$. It spans Qinghai, Gansu, and Inner Mongolia. It starts from Dahuang mountain in Shandan County in the east and borders the Shiyang River Basin. In the west, it borders on Heishan mountain, in Jiayuguan, and Shule River. In the south, it starts from the north-south watershed of Qilian Mountain, in Qilian county, and ends at the Juyanhai sea, in Ejina. In terms of administrative divisions, the upper reaches include Qilian County, in Qinghai Province; the middle reaches include Shandan County, Mingle County, Yugur Autonomous County of Sunan, Zhangye City, Linze County, Gaotai County, Jiayuguan City, and Jiuquan City, in Gansu Province; the lower reaches include Jinta County, in Gansu Province, and Ejina Banner, in Inner Mongolia.

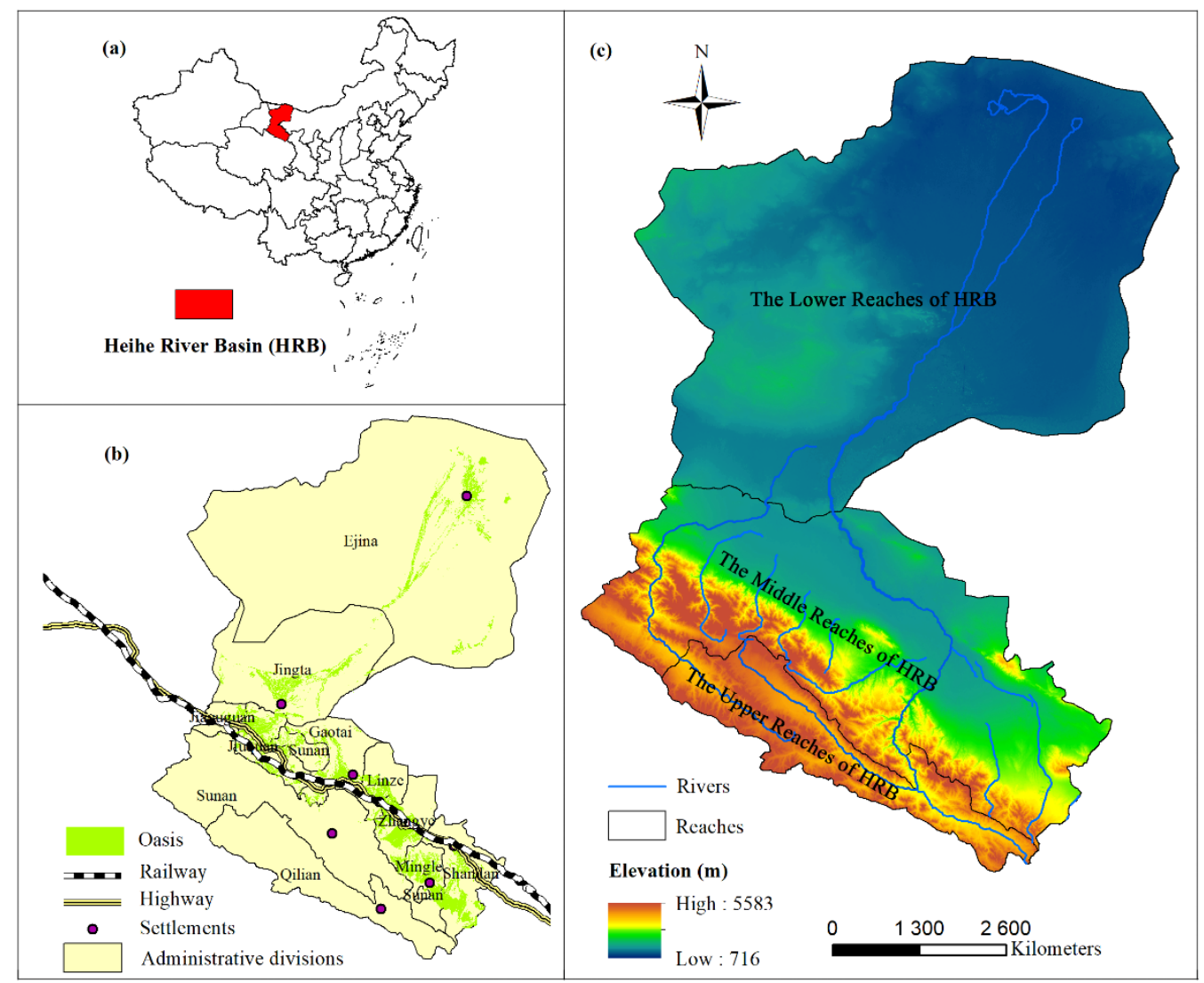

Figure 1. (a) Location of the HRB in northwest China, (b) map showing the 11 administrative divisions, and (c) relief map of the Heihe River Basin.

HRB is a typical continental arid climate. Due to the significant climate difference between the west-east and the south-north directions, HRB has a unique eco-hydrological process. It is an important ecological functional area for water yield, soil conservation, biodiversity protection, windbreak, and sand fixation in northwest China. The icy snow 
forest belt in the Qilian Mountain area in the upper reaches is the source and conservation area of water resources in the whole basin. Zhangye oasis, in the middle reaches, is the largest continuous artificial oasis in the arid area of northwest China. There are mainly deserts in the lower reaches. The Ejina oasis is an important ecological barrier to control the westward and southward migration of the Badain Jaran Desert and slow down the sandstorm [35]. The dataset of the oasis is provided by Liao Jie (Key Laboratory of Desert and Desertification, Northwest Institute of Eco-Environment and Resources, CAS)

\subsection{Operational Framework of the Spatial Pattern of WESs and Grassland-Grazing Capacity}

To quantify the impact of land use on ecosystem services and evaluate the grasslandgrazing capacity in HRB, we propose an operational framework (Figure 2). First, the land-use change in HRB was analyzed using the transfer matrix by ArcGIS for 2000-2018. The InVEST model was used to estimate the ecosystem services under alternative land use and fixed climate change. The focus was mainly on the different ways in which land use by humans results in spatial and temporal changes in WESs. Secondly, using RS and GIS technology, from the perspective of ecological factors and management, the annual grass yield is estimated according to the grassland type. Built on the analysis of the data of grassland distribution, nature reserve, distance from a water source, slope, and soil erosion intensity, a suitable area for grazing was obtained. Finally, we conducted a tradeoff analysis between the livestock-carrying capacity and WESs. In order to prevent soil erosion, water pollution, biodiversity protection, and other ecological compensation needs, the remaining part after deducting the above ecological need is the forage biomass for livestock to eat, in order to obtain the grazing amount of diverse areas and give some suggestions for grassland protection.

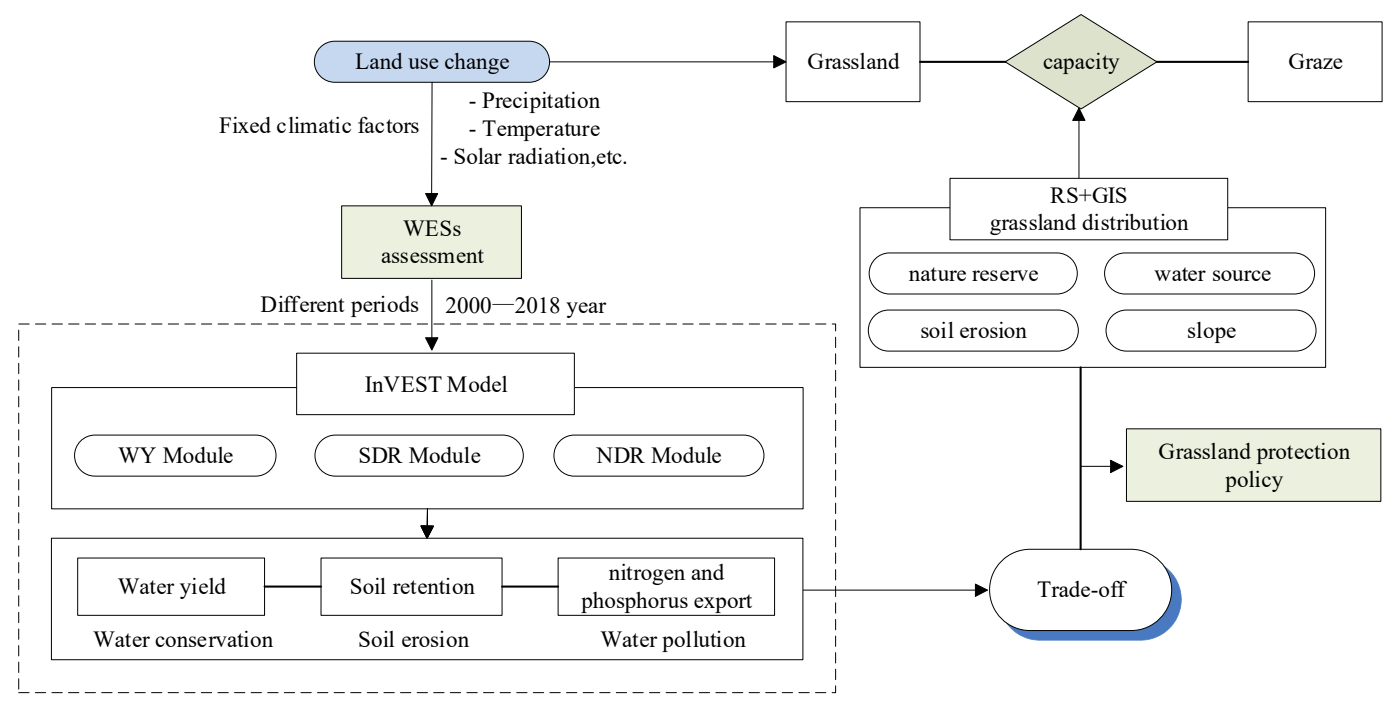

Figure 2. Methodological framework applied in the present analysis. WY = water yield; SDR = sediment delivery ratio; $\mathrm{NDR}=$ nutrient delivery ratio.

\subsection{Land-Use Change}

Land-use data with a spatial resolution of $30 \mathrm{~m}$ were downloaded from the National Earth System Science Data Center (http:/ / www.geodata.cn/, accessed on 8 February 2020). According to the remote sensing investigation and assessment system of China's ecological environment change, we divided land-use types into seven categories: forest, shrubland, grassland, wetland, cultivated, developed, and bare land.

The land-use transfer matrix reflects the dynamic process information of mutual transformation between local class areas at the beginning and end of a certain period in a certain region. It includes not only the static local class area data at a certain time point in a certain region, but also more abundant information about the transfer out of local class 
areas at the beginning and transfer into local class areas at the end of the period [36,37]. The general form of the land-use transfer matrix is:

$$
s_{i j}=\left[\begin{array}{cccc}
s_{11} & s_{12} & \ldots & s_{1 n} \\
s_{21} & s_{22} & \ldots & s_{2 n} \\
\ldots & \ldots & \ldots & \ldots \\
s_{n 1} & s_{n 2} & \ldots & s_{n n}
\end{array}\right]
$$

where $s_{i j}$ is the land area, $n$ is the number of land-use types, and $i$ and $j$ are the serial numbers of land-use types at the beginning and end of the study period, respectively.

\subsection{Modeling WESs}

We evaluated how LULC influenced the provision of these WESs in HRB from 2000 to 2018. After examining the relative importance of different WESs in HRB, we focused on three WESs: water yield, soil retention, and water purification. We used the Water Yield module in the InVEST model to evaluate spatial-temporal changes in the water provision service in HRB, the Sediment Delivery Ratio module to evaluate spatial-temporal changes in the soil retention service, and the Nutrient Delivery Ratio module to evaluate spatial-temporal changes in the water purification service. The InVEST (Version 3.6.0; Supplementary Information) suite of tools enables decision-makers to assess tradeoffs between ecosystem services and to compare the consequences of different future change scenarios, like land use and climate change. Details of these models, their modules, and their governing equations are provided in the Supplementary Information (SI, parts 1.1-1.3). The availability and sources of the data used, as well as the relevant input parameters, are presented in Tables S2-S4 in SI. All spatial data required by the model were prepared by ArcGIS 10.2.

The Water Yield module is an estimation method based on the water balance. The precipitation in each pixel minus the actual evapotranspiration is taken as a water yield. Actual evapotranspiration is estimated according to the algorithm proposed by [38] based on Budyko's hypothesis of water-heat coupling equilibrium. Soil retention refers to the capture of rain-eroded soil by vegetation or forest cover, which is utilized to protect soil resources and water quality. The Sediment Delivery Ratio module in InVEST uses a sediment transport model to represent the process of soil sediment generation and transport to rivers. For the water purification, based on land-use change and different nitrogen and phosphorus loading capacity, the nutrient sources in the whole landscape are determined in the Nutrient Delivery Ratio module, and the amount of nitrogen and phosphorus transported to rivers is calculated to assess the change in water quality. Water pollution is reduced by reducing the number of nitrogen and phosphorus flowing into rivers.

\subsection{Determination of the Suitable Grazing Area and Carrying Capacity}

According to the requirements of ecological protection, ecological vulnerability, landuse/cover type, etc., the unsuitable and non-grazing areas are defined, mainly including [27,39]: (1) Protected areas established according to the law in national nature reserves; (2) the areas with a water source distance of more than $3.2 \mathrm{~km}$; (3) ecological degradation areas with a strong soil erosion intensity, of IV, V, and VI; (4) areas with a slope greater than $40^{\circ}$; (5) non-grass areas such as forest land, cultivated land, construction land, wetland, and bare land. The suitable grazing area of HRB is delineated based on the spatial overlay analysis of the protection area, water source, soil erosion, a digital elevation model, land use, and so on.

The grassland types in the upper, middle, and lower reaches of HRB are quite different. Depending on the research results at home and abroad, the proportions of the forage biomass of high-coverage grassland, medium-coverage grassland, and low-coverage grassland in the total forage biomass are, respectively, $65 \%, 75 \%$, and $85 \%$ [27]. At the same time, according to the calculation and verification of grass geologists [40], it is pointed out that 
at least $50 \%$ of the forage biomass is used to prevent soil erosion and plant communities from experiencing drought (areas with insufficient water yield) and the need for postgrazing regeneration and elastic recovery. To prevent soil erosion, water pollution (areas with high nitrogen and phosphorus export), biodiversity protection, and other ecological compensations required that the forage biomass be set at $50 \%$. The remaining part of the grassland biomass in these areas after deducting the above-mentioned ecological need is the forage biomass available for livestock to eat. The Heihe River Basin is mainly composed of improved fine wool sheep and Tibetan sheep. The daily eclipse is determined as $4 \mathrm{~kg}$. The carrying capacity of natural grassland is 0.009 2.055 sheep per hectare [27]. Therefore, the natural grassland-carrying capacity and the grassland livestock capacity in HRB can be expressed as follows:

$$
\mathrm{S}=\sum_{i=1}^{n} \frac{F_{i}\left(1-E_{i}\right)}{G} A_{i}
$$

In the formula, $\mathrm{S}$ is the carrying capacity, $F_{i}$ is the unit grass yield of grassland type $i$; $E_{i}$ is the ecological biomass allocation of grassland type $i$. $G$ is the herbivorous amount of sheep, $A_{i}$ is the area of grassland type $i ; n$ is the number of grassland types.

\subsection{Data Requirement and Preparation}

The InVEST model requires multiple gridded datasets together with specific biophysical data as inputs, including digital elevation map (DEM) data $(30 \times 30 \mathrm{~m})$ downloaded from the Geospatial Data Cloud (http:/ / www.gscloud.cn/, accessed on 8 February 2020). The spatial data on HRB and other relevant data used in this study are summarized in Table S4 in SI, including a brief introduction, a summary of each dataset, related model principles, and the key parameters used in the InVEST model. All raster layers have a resolution of $30 \times 30 \mathrm{~m}$. The coordinate system is WGS_1984_Albers. The spatial distribution data on precipitation, radiation, and temperature in 2000 and 2018 were obtained by a Kriging interpolation (Figure S1 in SI) with a spatial resolution of $30 \times 30 \mathrm{~m}$ in ArcGIS 10.2. Since climate change has little impact on the study of the livestock-carrying capacity, natural factors such as precipitation, temperature, solar radiation, etc. were fixed as invariants.

\section{Results}

\subsection{Land-Use Change}

From the upper, middle, and lower reaches of HRB (Table S5 in SI), the bare land in the upper reaches increased by $768.80 \mathrm{~km}^{2}$, and the grassland and wetland decreased by $422.36 \mathrm{~km}^{2}$ and $678.48 \mathrm{~km}^{2}$, respectively. In the middle reaches, grassland decreased significantly, reaching $7778.03 \mathrm{~km}^{2}$, and bare land increased by $6521.55 \mathrm{~km}^{2}$. The grassland in the lower reaches increased by $7080.34 \mathrm{~km}^{2}$, and the bare land decreased by $7089.54 \mathrm{~km}^{2}$. There are obvious changes in the middle and lower reaches and just the opposite development trend. In the middle reaches, the number of grasslands decreased, while the bare land increased significantly, but in the lower reaches, the bare land decreased and the grassland increased.

The spatial distribution of HRB is mainly grassland and bare land (Figure 3). Among them, grassland is concentrated in the upper and middle reaches, and bare land is concentrated in the lower reaches. From 2000 to 2018, the change of the grassland area increased significantly and concentrated on the east side of the lower area. The forest and cultivated land are decreasing, developed and bare land is slightly decreasing, and wetland is basically unchanged. However, although the construction land is decreasing, in terms of spatial distribution, developed land becomes more scattered. 


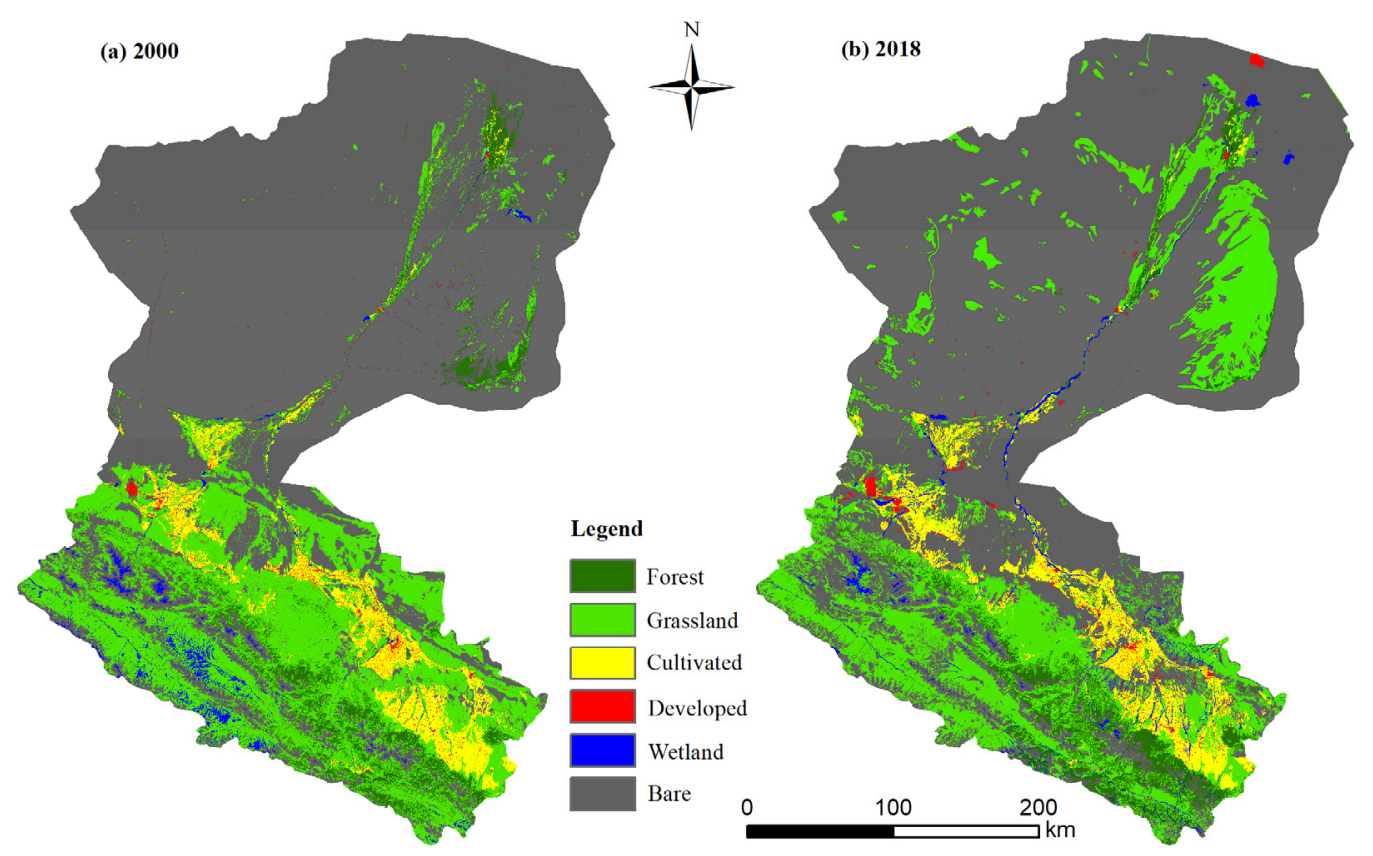

Figure 3. Land use/land cover in the Heihe River Basin in (a) 2000 and (b) 2018.

In 2000, the area of grassland and bare land was $28,624.09 \mathrm{~km}^{2}$ and $84,999.69 \mathrm{~km}^{2}$, respectively, accounting for $22.31 \%$ and $66.25 \%$ of the total area. In 2018, the area of grassland and bare land was $29,756.71 \mathrm{~km}^{2}$ and $84,805.99 \mathrm{~km}^{2}$, respectively, accounting for $23.19 \%$ and $66.10 \%$ of the total drainage area (Table 1). From 2000 to 2018, the increase of grassland was mainly due to the transformation of bare land, reaching $10,858.44 \mathrm{~km}^{2}$. At the same time, $10,685.39 \mathrm{~km}^{2}$ of grassland have been converted to bare land. That is: bare land and grassland are frequently changing into one another. In 2018, the area of forest was $5330.03 \mathrm{~km}^{2}$, which was mainly transformed from grassland and bare land, reaching $1791.01 \mathrm{~km}^{2}$ and $639.66 \mathrm{~km}^{2}$, respectively. Meanwhile, in 2000, the area of forest land was $5857.63 \mathrm{~km}^{2}$, which was mainly transformed into grassland and bare land, reaching $2435.86 \mathrm{~km}^{2}$ and $505.47 \mathrm{~km}^{2}$, respectively. In other words, forests, grassland, and bare land are also changing frequently. In 2000 and 2018, the cultivated land area was $6358.48 \mathrm{~km}^{2}$ and $6066.47 \mathrm{~km}^{2}$, respectively, and the transfer area with other land types was not large. However, the proportion of developed land in the whole basin area is very small, less than $7 \%$, although the scope of transfer is very large. In 2018, the developed land area was $756.67 \mathrm{~km}^{2}$, which was mainly converted from cultivated land and bare land, amounting to $305.4 \mathrm{~km}^{2}$ and $131.98 \mathrm{~km}^{2}$, respectively. In 2000, the developed land area was $867.33 \mathrm{~km}^{2}$, mainly converted into grassland and cultivated land, followed by bare land. Finally, the developed land became more spatially dispersed. In 2000 and 2018, the wetland areas were $1588.86 \mathrm{~km}^{2}$ and $1580.21 \mathrm{~km}^{2}$, respectively. Although the total amount was basically unchanged, the conversion range was also large. In 2018, wetlands were mainly converted from grassland and bare land, which amounted to $647.49 \mathrm{~km}^{2}$ and $532.32 \mathrm{~km}^{2}$, respectively. From 2000 to 2018, wetlands were mainly turned into grassland and bare land. It can be observed that the types of land use in the HRB have changed frequently in the past 18 years.

\subsection{The Distribution Change of Grassland Coverage}

The types of grassland coverage are obtained by RS and GIS (Figure 4). In terms of spatial distribution, the area of low coverage grassland occupied the largest, while the area of high coverage and medium coverage was much smaller. The high-covered grassland is mainly concentrated in the upper reaches of the Qilian mountains area. In 2000, the medium-covered grassland was mainly concentrated in the middle reaches, while in 2018 the medium-covered grassland was located more in the east of the lower reaches. 
Table 1. Land-use/land-cover (LULC) transition matrix for HRB, 2000-2018 (units = $\mathrm{km}^{2}$ ).

\begin{tabular}{ccccccccc}
\hline & & $\mathbf{2 0 1 8}$ & & & & & \\
& & Forest & Grassland & Cultivated & Developed & Wetland & Bare & Total \\
\hline \multirow{2}{*}{$\mathbf{2 0 0 0}$} & Forest & 2754.12 & 1791.01 & 84.16 & 8.25 & 52.83 & 639.66 & 5330.03 \\
& Grassland & 2435.86 & $14,855.38$ & 862.93 & 199.55 & 544.55 & $10,858.44$ & $29,756.71$ \\
& Cultivated & 99.03 & 576.69 & 4732.79 & 237.08 & 88.54 & 332.34 & 6066.47 \\
& Developed & 9.96 & 68.13 & 305.4 & 231.78 & 9.42 & 131.98 & 756.67 \\
& Wetland & 53.19 & 647.49 & 21.17 & 2.83 & 323.21 & 532.32 & 1580.21 \\
& Bare & 505.47 & $10,685.39$ & 352.03 & 187.84 & 570.31 & $72,504.95$ & $84,805.99$ \\
& Total & 5857.63 & $28,624.09$ & 6358.48 & 867.33 & 1588.86 & $84,999.69$ & $128,296.08$ \\
\hline
\end{tabular}

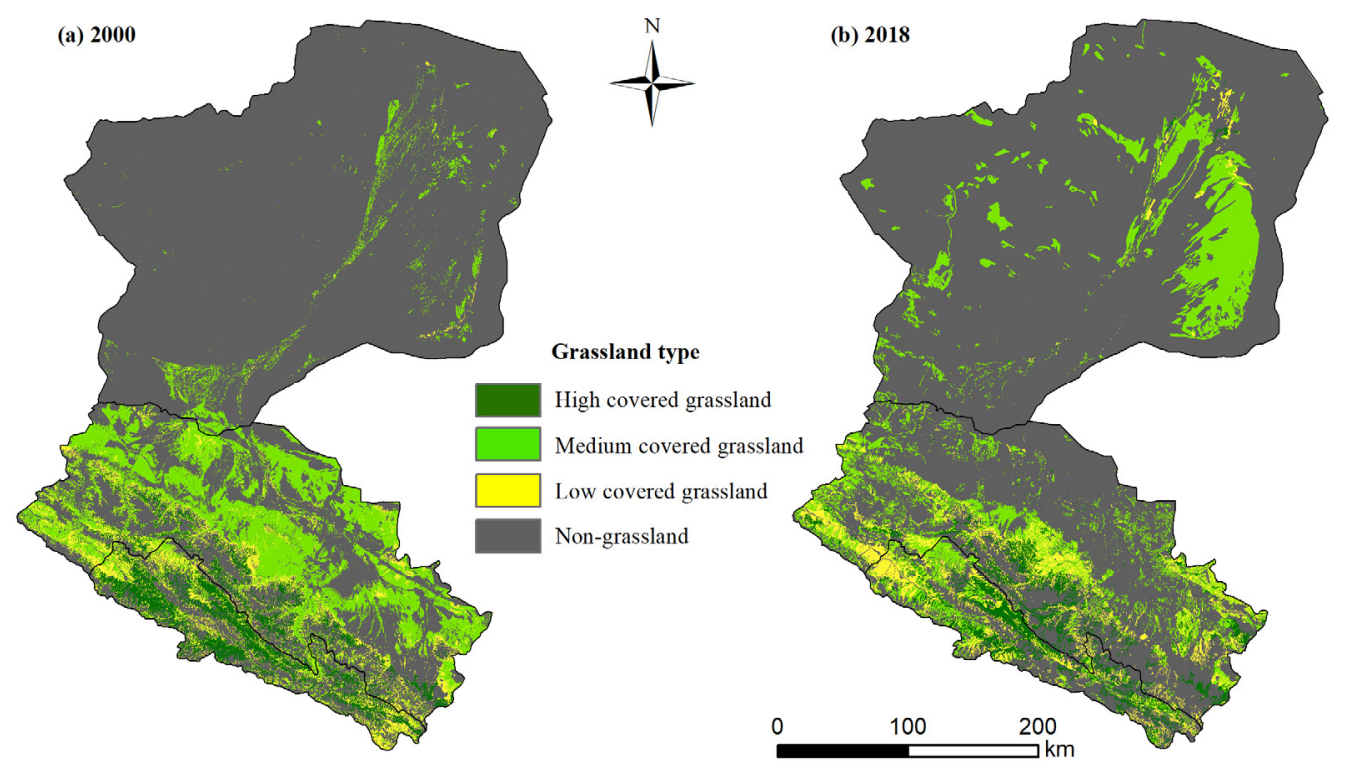

Figure 4. Spatial distribution of grassland type in the Heihe River Basin (a) 2000; (b) 2018.

In 2000, the area of high-covered grassland, medium-covered grassland, and lowcovered grassland was $5187.21 \mathrm{~km}^{2}, 5944.10 \mathrm{~km}^{2}, 18625.68 \mathrm{~km}^{2}$, respectively, accounting for $4.04 \%, 4.63 \%$, and $14.52 \%$, respectively. By 2018 , the area of grassland coverage was $4501.80 \mathrm{~km}^{2}, 6343.97 \mathrm{~km}^{2}$, and $17724.77 \mathrm{~km}^{2}$, which accounted for $3.51 \%, 4.95 \%$, and $13.82 \%$, respectively (Table 2). Obviously, the area of high-covered grassland and lowcovered grassland was decreasing, while that of the medium-coverage grassland and non-grassland was increasing.

Table 2. The type of grassland coverage in the Heihe River Basin from 2000 to 2018.

\begin{tabular}{ccccccc}
\hline $\begin{array}{c}\text { Grassland } \\
\text { Covered } \\
\text { Type }\end{array}$ & $\mathbf{2 0 0 0}$ & $\begin{array}{c}\text { Area } \\
\left(\mathbf{k m}^{2}\right)\end{array}$ & $\mathbf{2 0 1 8}$ & $\mathbf{2 0 0 0}$ & $\mathbf{2 0 1 8}$ & $\begin{array}{c}\text { Percent } \\
\mathbf{( \% )}\end{array}$ \\
\hline High & 5187.21 & 4501.80 & 4.04 & 3.51 & $\begin{array}{c}\text { Carrying Capacity } \\
\text { Reference } \\
\text { Reduced (\%) }\end{array}$ & $\begin{array}{c}\text { Ecological } \\
\text { Compensation } \\
\text { Reference Needs (\%) }\end{array}$ \\
Medium & 5944.10 & 6343.97 & 4.63 & 4.95 & 15.00 & 50.00 \\
Low & $18,625.68$ & $17,724.77$ & 14.52 & 13.82 & 35.00 & 50.00 \\
Non-grassland & $98,541.54$ & $99,679.29$ & 76.81 & 77.72 & 0.00 & 50.00 \\
\hline
\end{tabular}




\subsection{Ecosystem Services Change}

\subsubsection{Water Yield}

WESs in HRB showed various spatial patterns and changes during the study period (Table 3). In 2000, the total water yield of the basin was 5.77 billion $\mathrm{m}^{3}$, while in 2018 it was 5.88 billion $\mathrm{m}^{3}$ (Figure 5). Thus, the total water yield displayed an upward trend. The highest water yield in 2000 and 2018 was $642.47 \mathrm{~mm}$ and $649.93 \mathrm{~mm}$, respectively (Figure 5). The areas with high water yield are mainly concentrated in the Qilian Mountains in the upper and middle reaches, while the water yield in the lower reaches is very little. In addition, the water yield is staggered, increasing or decreasing in most regions. Since the lower reaches have little water yield, and in many areas no yield at all, there is no change in this region from 2000 to 2018 (Figure 5c).

Table 3. Total amount of water-related ecosystem services in the Heihe River Basin in 2000 and 2018.

\begin{tabular}{ccc}
\hline Water-Related Ecosystem Services & $\mathbf{2 0 0 0}$ & $\mathbf{2 0 1 8}$ \\
\hline Total area of Heihe River Basin $\left(10^{4} \mathrm{~km}^{2}\right)$ & 12.78 & 12.78 \\
Water yield $\left(10^{8} \mathrm{~m}^{3}\right)$ & 57.68 & 58.75 \\
Soil retention (ton) & $1,534,755,667.48$ & $1,579,632,228.14$ \\
Soil export (ton) & $2,720,496.55$ & $2,583,635.23$ \\
Soil loss (ton) & $1,537,476,164.03$ & $1,582,215,863.37$ \\
Nitrogen load (ton) & $72,870,558.36$ & $72,148,405.25$ \\
Nitrogen export (ton) & $22,635,007.61$ & $22,692,695.77$ \\
Nitrogen export (ton $\left./ \mathrm{km}^{2}\right)$ & 177.11 & 177.56 \\
Phosphorus load (ton) & $6,554,021.60$ & $6,513,306.43$ \\
Phosphorus export (ton) & $2,554,695.86$ & $2,387,522.85$ \\
Phosphorus export (ton $\left./ \mathrm{km}^{2}\right)$ & 19.99 & 18.68 \\
\hline
\end{tabular}
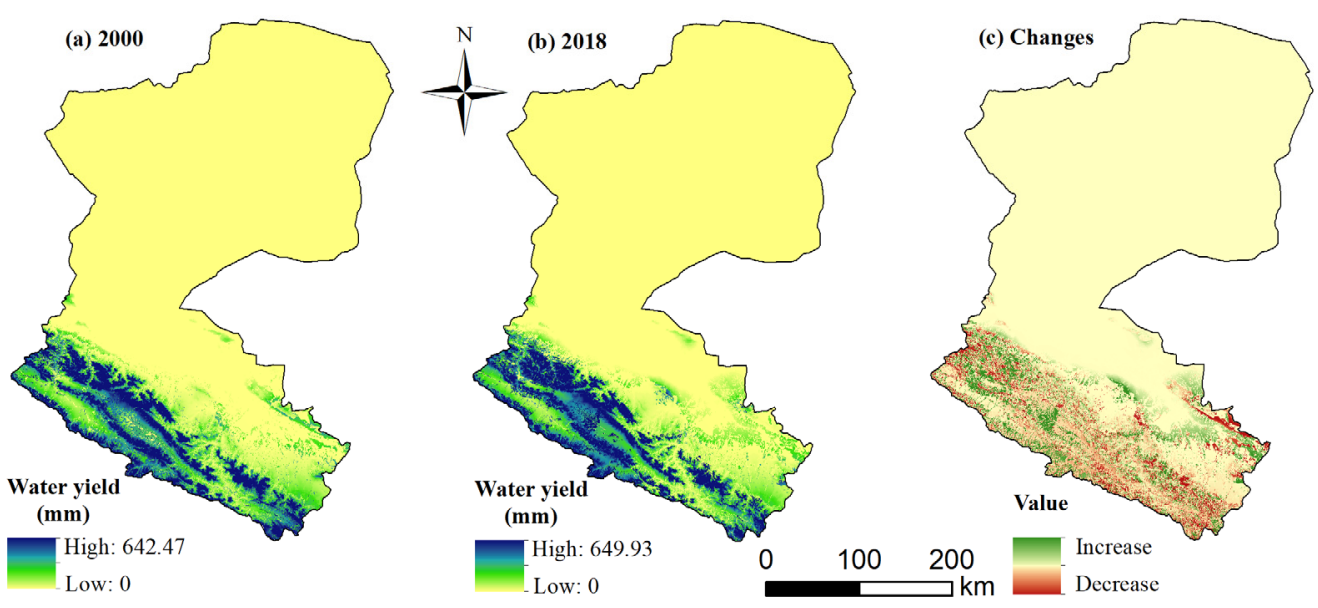

Figure 5. Spatial distribution and changes in water yield from 2000 to 2018. (a): water yield in 2000; (b): water yield in 2018; (c): changes from 2000 to 2018.

\subsubsection{Soil Retention}

The total soil retention in the basin increased slightly, from 1.53 billion $\mathrm{t}$ to 1.58 billion $\mathrm{t}$, between 2000 and 2018 (Figure 6, Table 3). The highest soil retention rate in 2000 and 2018 was $196.73 \mathrm{t} /$ ha and $202.98 \mathrm{t} /$ ha, respectively (Figure 6). The areas with high soil retention are also mainly concentrated in the Qilian Mountains in the upper and middle reaches, while the soil retention in the lower reaches is very little. What is more, soil retention increases or decreases alternately in most areas. Since the lower reaches have little soil retention, or even no retention at all, there is no change in this area from 2000 to 2018 (Figure 6c). 

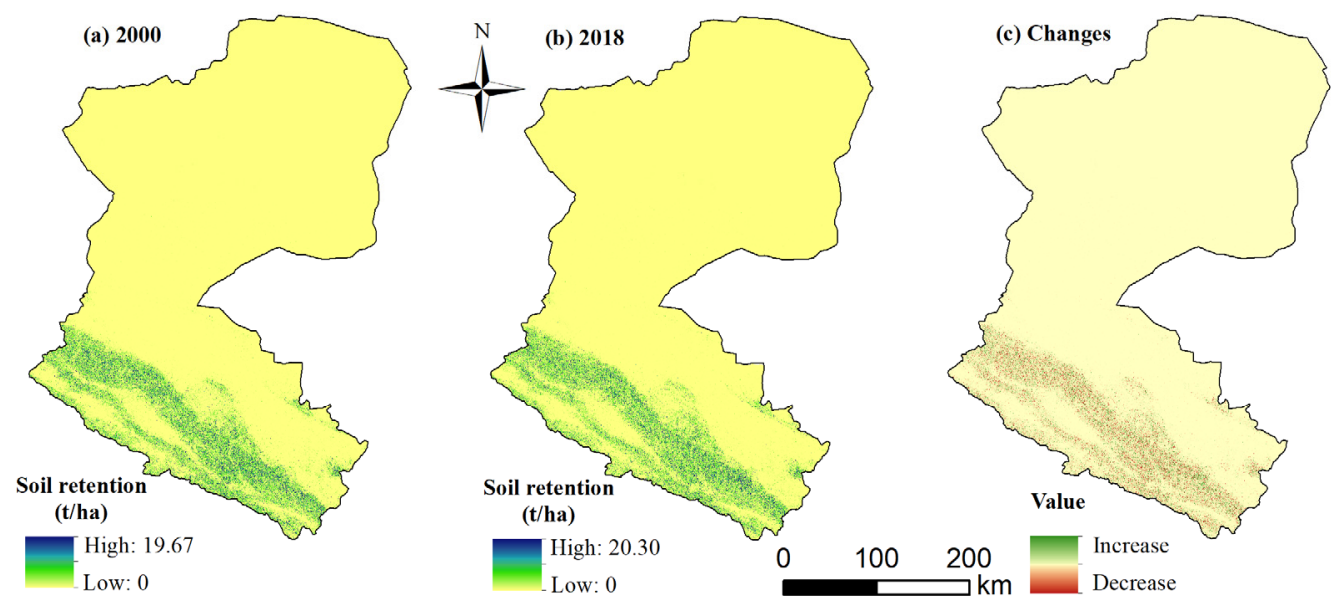

Figure 6. Spatial distribution and changes in soil retention from 2000 to 2015 (a): soil retention in 2000; (b): soil retention in 2015; (c): changes from 2000 to 2015.

\subsubsection{Soil Erosion}

In HRB, soil erosion is caused by land-use change and climate conditions, according to the Standard for Classification and Gradation of Soil Erosion (SL190-2007) issued by the Ministry of Water Resources of China (http://www.mwr.gov.cn/, accessed on 8 February 2020). Based on the statistical results of the soil erosion transfer matrix (Table S6 in SI), we obtained the spatial layout of soil erosion modulus (Figure 7). Soil erosion was divided into six levels. It could be found that the spatial changes of soil erosion were basically coincident from 2000 to 2018, and soil erosion was worst in the bottom of the east area. Overall, soil erosion was little in most of the area.

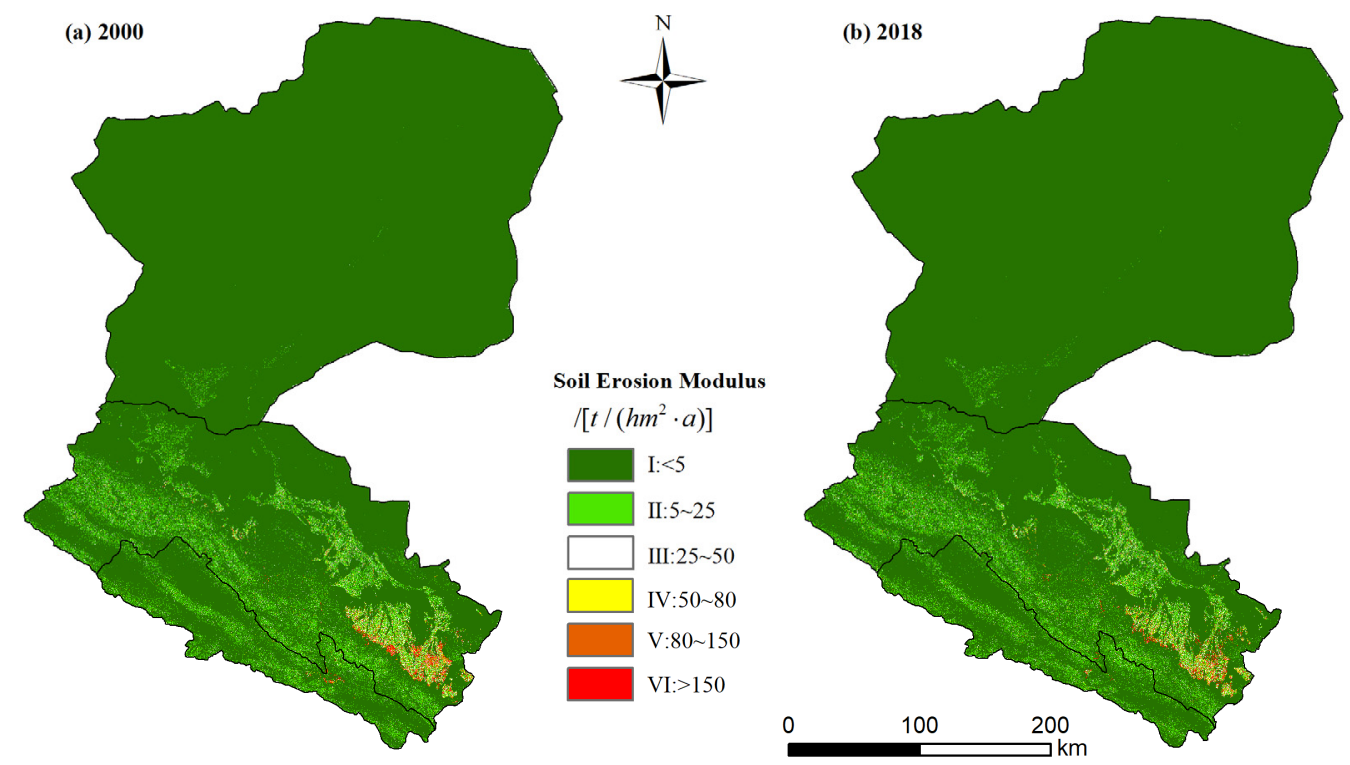

Figure 7. Spatial distribution and changes in soil erosion from 2000 to 2018 (a): soil erosion in 2000; (b): soil erosion in 2018.

According to the area proportion of the soil erosion modulus (Table 4), it could be noted that the proportion of grade I about the soil erosion modulus was the highest, which was $92.78 \%$ and $92.72 \%$, respectively. Meanwhile, the grade I erosion modulus accounted for more than $92 \%$ and indicated that HRB was generally less affected by soil erosion. However, from 2000 to 2018, the area of the soil erosion modulus at grades III, IV, V, and VI had been increasing, which indicated that soil erosion has been gradually expanding in the past 18 years. 
Table 4. The percentage of soil erosion level in the Heihe River Basin from 2000 to 2018. (unit: \%).

\begin{tabular}{ccccccc}
\hline Erosion Level & I & II & III & IV & V & VI \\
\hline 2000 & 92.78 & 5.53 & 0.87 & 0.33 & 0.25 & 0.23 \\
2018 & 92.72 & 5.52 & 0.88 & 0.35 & 0.27 & 0.26 \\
\hline
\end{tabular}

\subsubsection{Nitrogen and Phosphorus Export}

The total nitrogen export from HRB rose from 22,635,007.61 t to 22,692,695.77 $\mathrm{t}$ between 2000 and 2018 (Figure 8, Table 3). It was found that from 2000 to 2018, the highest nitrogen export rate was $2.11 \mathrm{~kg} / \mathrm{ha}$ (Figure 8). The spatial changes in nitrogen export were basically coincident and increases in nitrogen export were concentrated in the upper and middle reaches of the basin.
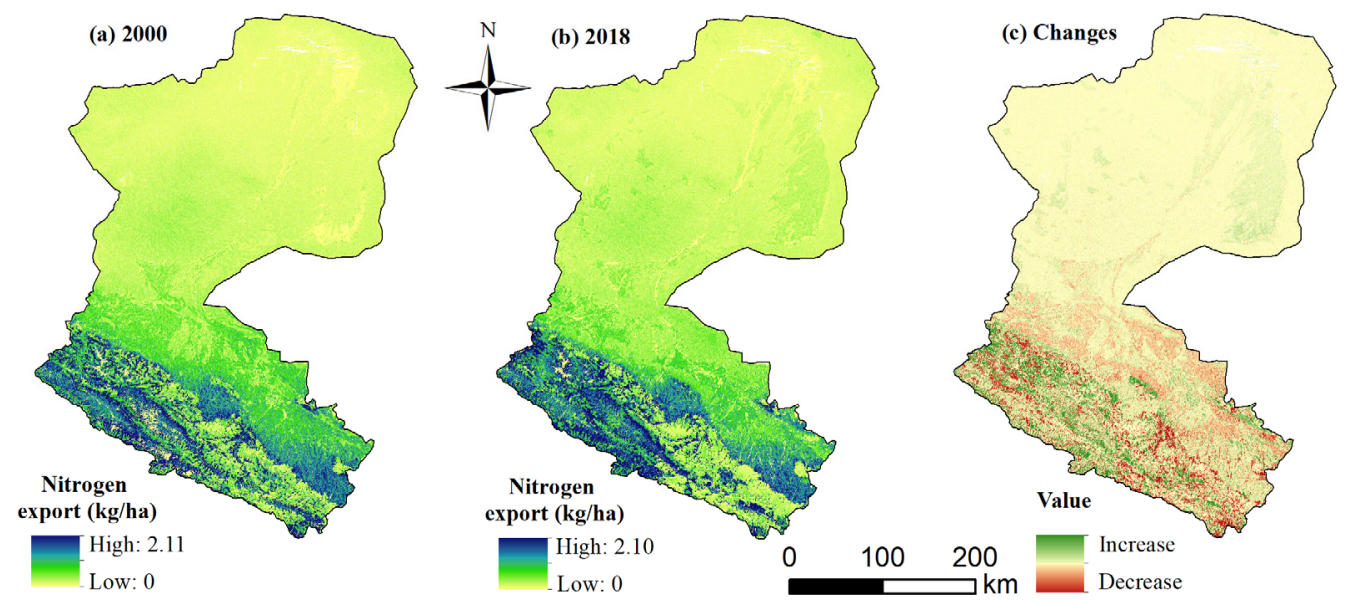

Figure 8. Spatial distribution and changes in nitrogen export from 2000 to 2018 (a): nitrogen export in 2000; (b): nitrogen export in 2018; (c): changes from 2000 to 2018.

The total phosphorus export from the basin was 2,554,695.86 $\mathrm{t}$ in 2000 and 2,387,522.85 $\mathrm{t}$ in 2018 (Figure 8, Table 3). Thus, the total phosphorus export also showed a downward trend. In 2000-2018, the highest export rate was $2.10 \mathrm{~kg} / \mathrm{ha}$ (Figure 8). The spatial changes of phosphorus export were also basically coincident, and increases in phosphorus export were concentrated in the upper and middle reaches of the basin. In general, nitrogen and phosphorus export generally showed the same pattern of change from 2000 to 2018 (Figures 8 and 9). However, in terms of quantity, the nitrogen export is significantly higher than that of phosphorus. Meanwhile, the increase and decrease of nitrogen and phosphorus export are scattered in space and remain basically unchanged in the lower reaches.

\subsection{Identification of Suitable Grazing Areas}

Through an overlay analysis (Figures S2 and S3 in SI), the spatial distribution area which is suitable for grazing in HRB was obtained (Figure 10, Table S7 in SI). In 2000, the suitable area for grazing was $8439.51 \mathrm{~km}^{2}$, accounting for about $6.59 \%$ of the total area in HRB. In 2018, the suitable area for grazing was $5941.35 \mathrm{~km}^{2}$, accounting for about $4.64 \%$. From 2000 to 2018, the suitable area for grazing decreased. By 2018, in particular, it was less than $5 \%$ of the total area. From the perspective of spatial distribution, the suitable areas for grazing were concentrated in the upper reaches and a small part of the middle reaches in 2000 and 2018, while the areas suitable for grazing in the lower reaches were mainly in the middle of the eastern area. At the same time, in 2000, the grazing area in the upper reaches was obviously concentrated in Qilian county. By 2018, the grazing area became scattered, and Shandan county, in the middle reaches, increased significantly. 

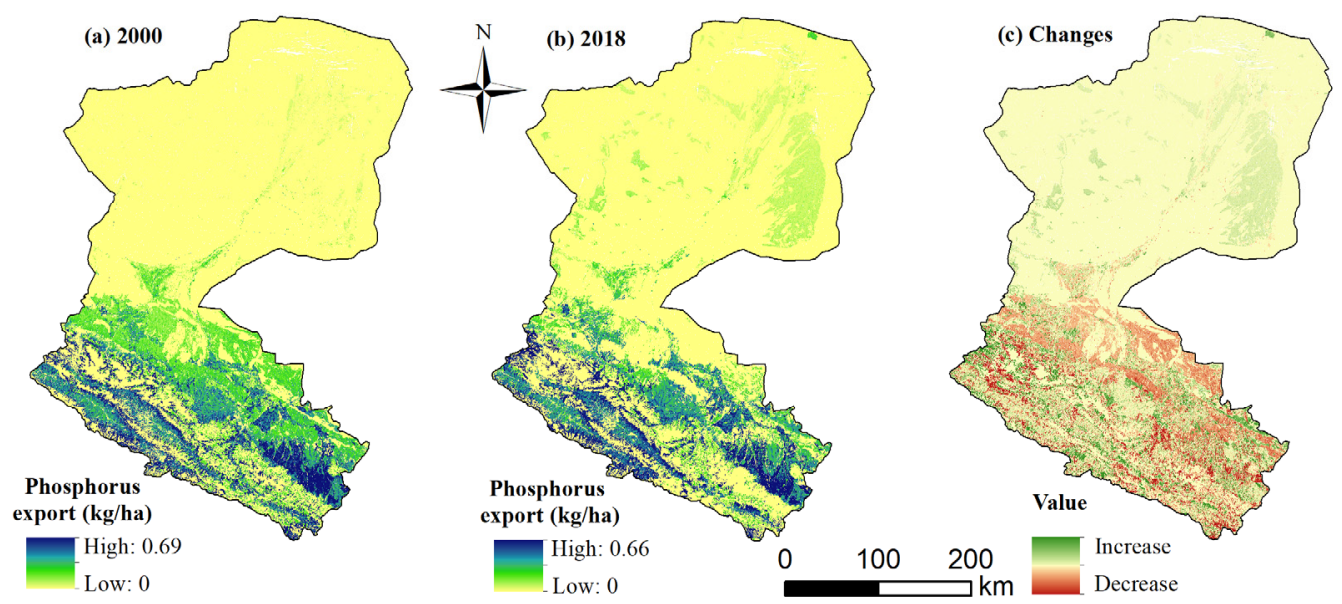

Figure 9. Spatial distribution and changes in phosphorus export from 2000 to 2018 (a): phosphorus export in 2000; (b): phosphorus export in 2018; (c): changes from 2000 to 2018.
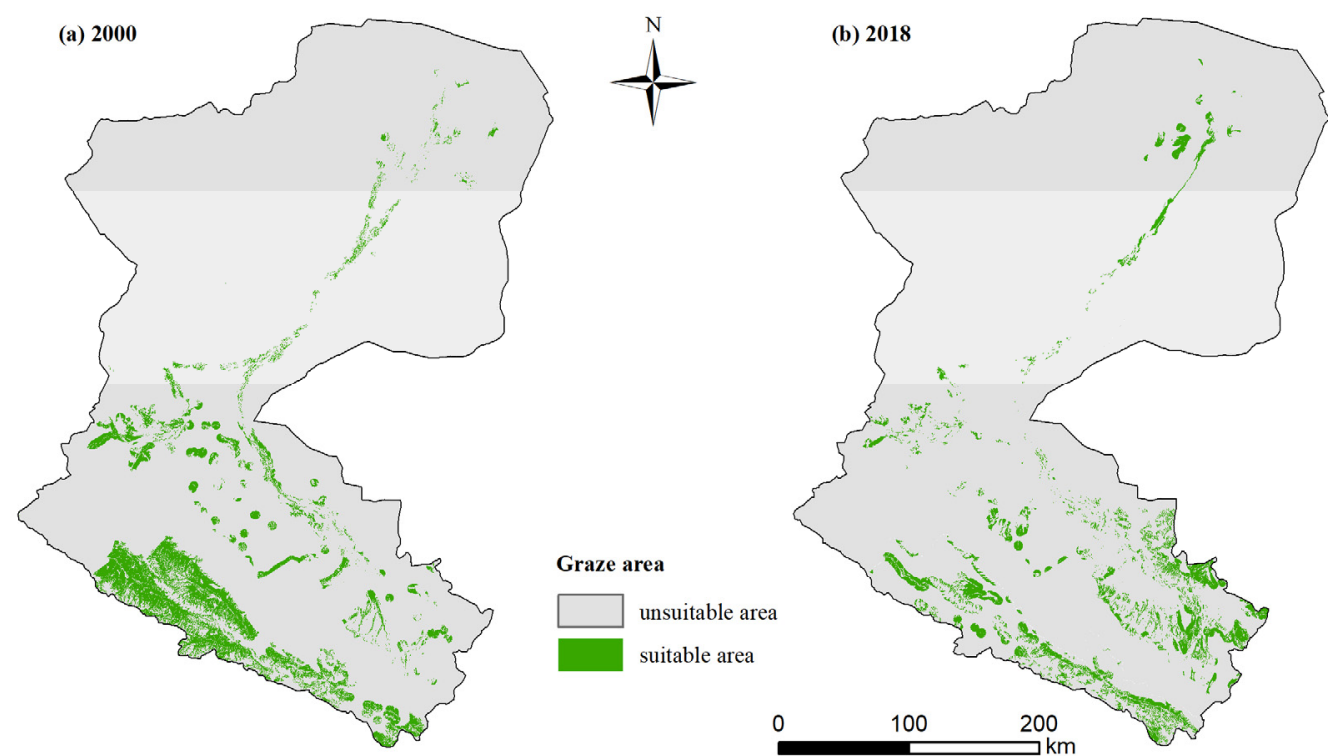

Figure 10. Spatial distribution of grazing suitable and unsuitable areas in (a) 2000 and (b) 2018.

\subsection{Identification of Suitable Carrying Capacity}

Based on the analysis of the suitable grazing area and the biomass ratio of different grassland types, the ecological compensation demand was deducted. We used Arcgis10.2 soft to carry out a statistical analysis of each different administrative area, to get the corresponding grazing area and carrying capacity (Table 5). Qilian county owns the largest suitable area and capacity for grazing, which are 5210.42 and 2256.29, respectively, accounting for $49.6 \%$ and $21.48 \%$; the carrying capacity is 1,155,600 and 813,500 . In 2000, the smallest suitable grazing area was Linze County, which was 182.21, accounting for $6.75 \%$, and had a carrying capacity of 25,000 . In 2018 , the smallest suitable grazing area was Jingta County, which was 95.87, accounting for $0.63 \%$, and the carrying capacity was 13,100 . Meanwhile, in 2018, the percentage of Shandan County suitable for grazing exceeded that of Qilian County, but the area suitable for grazing in Shandan County was still smaller than Qilian County. 
Table 5. The suitable graze area and carrying capacity in the Heihe River Basin from 2000 to 2018.

\begin{tabular}{ccccccc}
\hline \multirow{2}{*}{ County } & Suitable Graze Area $\left.\mathbf{( k m}^{\mathbf{2}}\right)$ & \multicolumn{2}{c}{ Percent (\%) } & \multicolumn{2}{c}{ Carrying Capacity $\left(\mathbf{1 0}^{\mathbf{4}}\right.$ sheep) } \\
& $\mathbf{2 0 0 0}$ & $\mathbf{2 0 1 8}$ & $\mathbf{2 0 0 0}$ & $\mathbf{2 0 1 8}$ & $\mathbf{2 0 0 0}$ & $\mathbf{2 0 1 8}$ \\
\hline Ejina & 379.13 & 584.73 & 0.61 & 0.94 & 5.19 & 8.01 \\
Jingta & 376.86 & 95.87 & 2.47 & 0.63 & 5.16 & 1.31 \\
Jiayuguan & 334.75 & 154.98 & 25.77 & 11.93 & 4.59 & 2.12 \\
Jiuquan & 494.16 & 190.24 & 14.20 & 5.47 & 6.77 & 2.61 \\
Sunan & 416.63 & 175.37 & 14.25 & 1.21 & 5.71 & 2.40 \\
Gaotai & 439.73 & 220.06 & 10.34 & 5.18 & 6.02 & 3.01 \\
Linze & 182.21 & 127.56 & 6.75 & 4.73 & 2.50 & 1.75 \\
Zhangye & 183.19 & 531.69 & 4.97 & 14.44 & 2.51 & 7.28 \\
Mingle & 222.53 & 348.86 & 7.66 & 12.01 & 3.05 & 4.78 \\
Shandan & 199.90 & 1255.69 & 3.98 & 25.01 & 2.74 & 17.20 \\
Qilian & 5210.42 & 2256.29 & 49.60 & 21.48 & 71.38 & 30.91 \\
\hline
\end{tabular}

According to the spatial distribution of each administrative division (Figure 11), high grazing is mainly concentrated in Qilian and Shandan Counties. From 2000 to 2018, the carrying capacity of Qilian County decreased, and that of Shandan County increased rapidly. At the same time, we found that the carrying capacity of Ejina, Zhangye, Mingle, and Shandan County were increasing, while that of the remaining counties was decreasing.

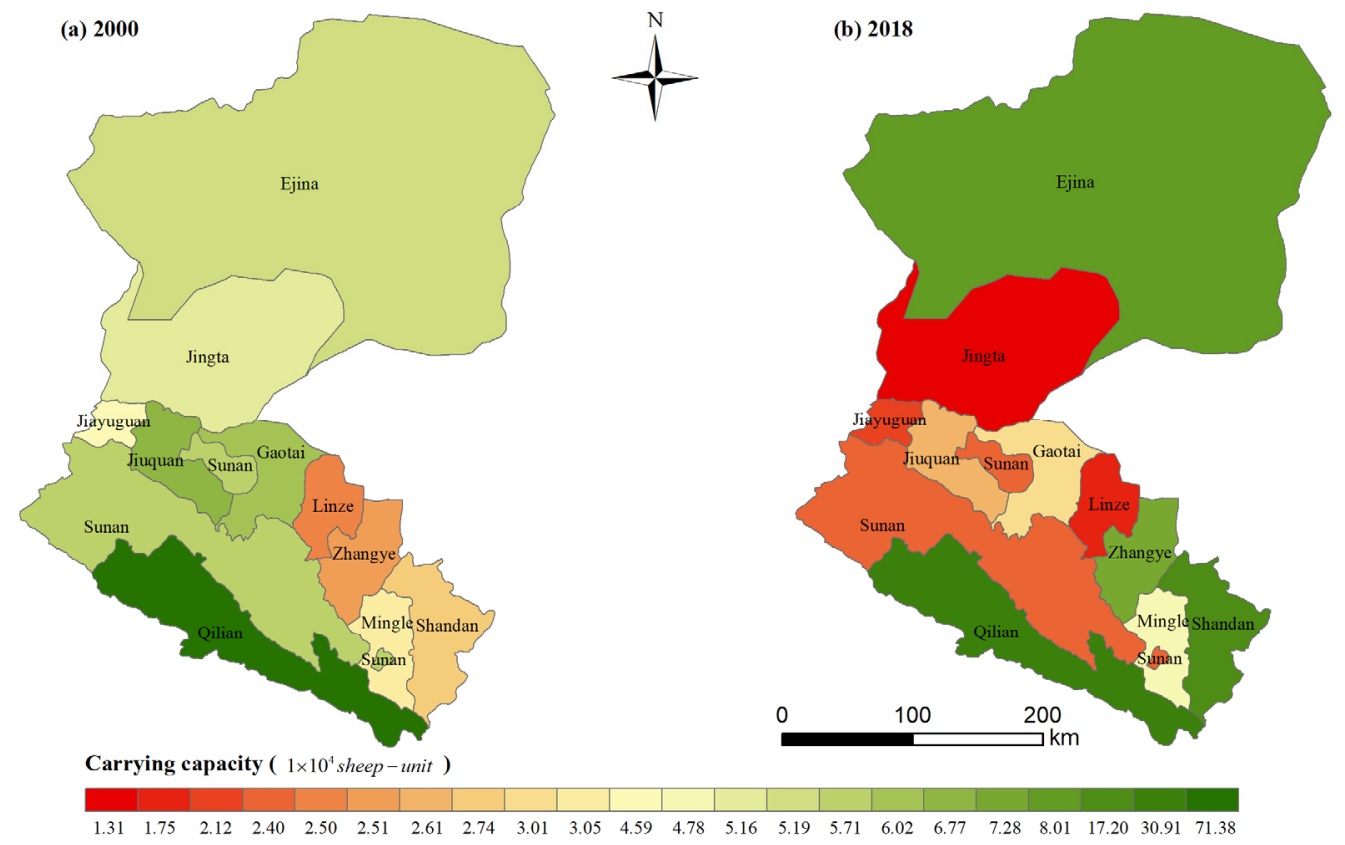

Figure 11. Spatial distribution of the carrying capacity in (a) 2000 and (b) 2018.

\subsection{Tradeoff Analysis}

In 2000, there was a positive correlation between the livestock-carrying capacity and water yield, and in 2018 the positive correlation decreased and was significantly weakened. In 2000, there was no correlation between the stocking capacity and nitrogen export, but in 2018 there was a strong positive correlation (Figure 12). We found that the grasslandcarrying capacity is achieved at the expense of the ecosystem services. 


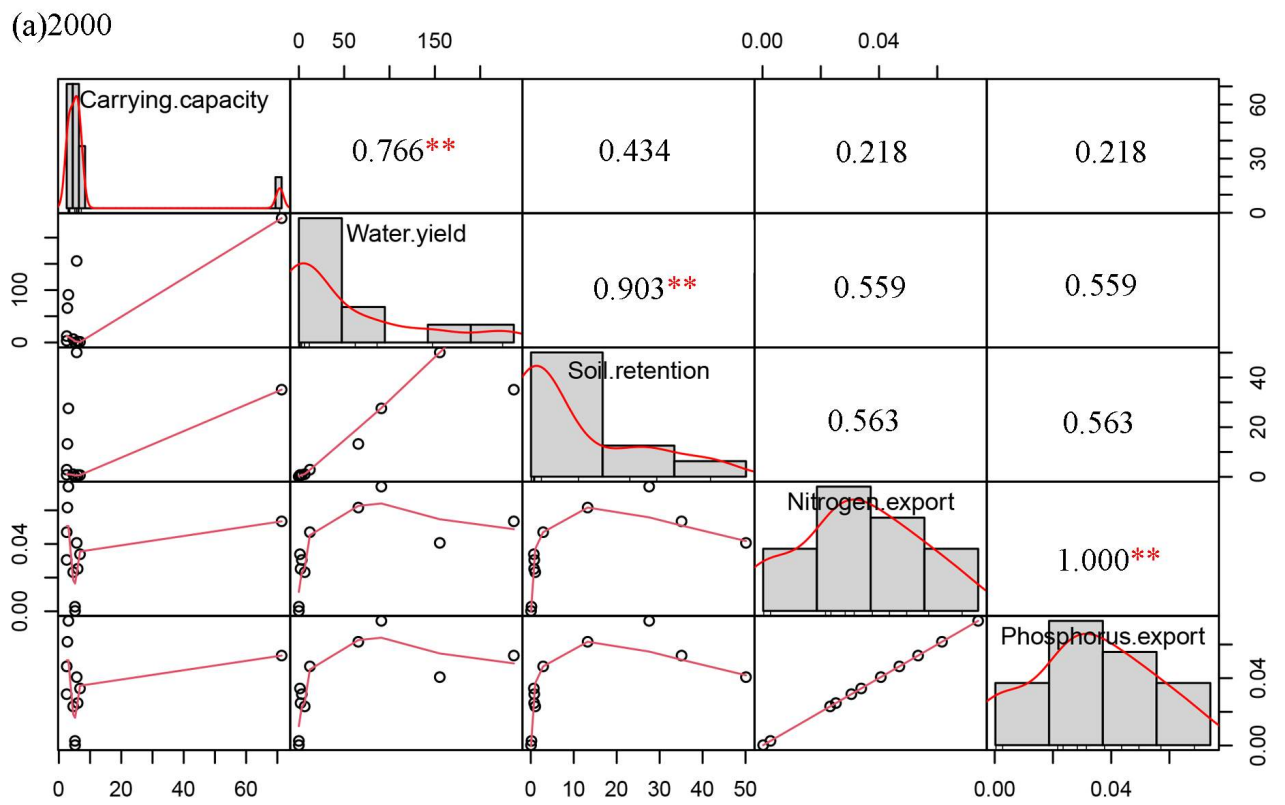

(b) 2018

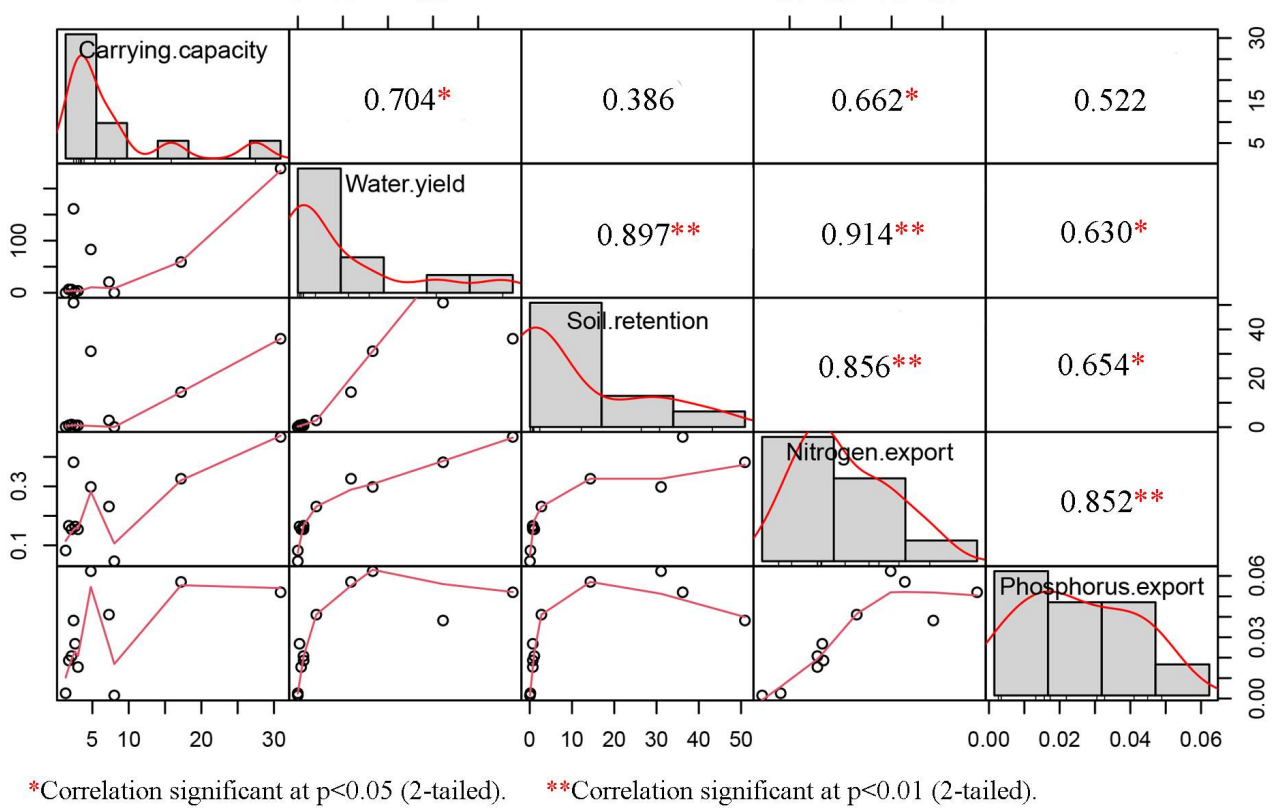

Figure 12. Pearson correlation coefficient $\left(\mathrm{R}^{2}\right)$ between carrying capacity and ecosystem services in HRB in (a) 2000 and (b) 2018.

\section{Discussion}

\subsection{Changes in Land Use and the Distribution of Grassland Coverage}

From the perspective of the reaches, the upper reaches of HRB are dominated by forest ecosystems and constitute water conservation areas of the whole basin. The change of landuse types is not obvious, indicating that the upper reaches' ecosystem basically remains unchanged. The middle reaches are dominated by oasis, desert, and grassland ecosystems, and oasis-irrigated agriculture is developed. In recent years, overgrazing has led to a sharp decrease in grassland and an obvious increase in bare land. Under the combined effect of the development of artificial oasis and afforestation activities in the lower reaches [28], grassland increased significantly and desertification expansion was significantly curbed. Compared with previous studies, the most significant finding is that the types of landuse transfer are more frequent than before 2000 [20]. From 2000 to 2018, bare land and 
grassland frequently changed into one another, and grassland was transferred from the middle reaches to the downstream area. Grassland was transferred from the middle reaches to the lower reaches, which indicates that the good grassland vegetation was gradually destroyed, while the bare land was developed through artificial vegetation conservation, ecological compensation, and other measures. From the perspective of grassland cover changes, due to the development of animal husbandry, high-coverage grasslands are gradually turning into middle-covered and low-covered grasslands.

By analyzing the changes in land use, land transfer matrix, and grassland distribution in the reaches, we can clearly understand the characteristics and problems of the land-use types in time and space from 2000 to 2018. Aiming at these problems, a series of water and soil resource management measures and ecosystem restoration projects were implemented [21], such as the implementation of the "Ecological Protection and Restoration Program (EPRP)" [3] and the "Ecological Protective Forest Project of HRB", the "Gansu Qilian Mountain National Nature Reserve", and the "Zhangye Heihe Wetland National Nature Reserve", which have achieved a very good effect. Therefore, in the context of rapid climate change, over-exploitation of grassland resources, and continuous ecological construction, we should know that good ecological protection measures must be maintained and shortcomings must be improved. It is of great significance to study the relationship between the spatiotemporal change of the ecosystem and its carrying capacity in HRB for mitigating and adapting to the ecological consequences of climate change, optimizing the allocation of water and soil resources and evaluating the performance of ecological protection policies.

\subsection{Potential Water-Related Ecological Vulnerability}

The total amount of water yield in HRB is increasing. Under the condition of constant precipitation, this indicates that evapotranspiration is decreasing and that the influence of forest-covered and grassland vegetation covered by the surface is weakening. Especially in the middle reaches, the continuous reduction of the water yield has induced and accelerated the development of land desertification. Although the total amount of soil retention is increasing, it is only concentrated in the upper reaches of the Qilian Mountains, and the middle and lower reaches are weakening, so it is necessary to plan a careful vegetation restoration in the middle and lower reaches. Due to the development of large-scale irrigated farmland and human activities, it may be the main cause of regional soil erosion that is further intensified [41,42]. The nitrogen and phosphorus export are mainly concentrated in the upper and middle reaches. As agriculture is the pillar industry in the middle reaches, the application of agricultural chemical fertilizer and pesticide is one of the important reasons for the non-point source pollution of surface water quality [43], which shows that the human gathering area has greater ecological pollution [44]. With the acceleration of regional urbanization and the development of the industrial economy, water pollution should never be optimistic. As a result of the increase in nitrogen and phosphorus in water, the conflict between the supply and demand of regional water resources will be exacerbated. Therefore, while doing ecological restoration projects, we must also reduce the ecological damage and pollution caused by human beings and carry out the double treatment.

In a word, the change of the watershed ecological environment is mainly the result of human activities. Although regional climate change also plays a certain role, the impact of human activities is the most controllable, and the fluctuations of climate have exacerbated the impact of human activities. Using the InVEST model to simulate the output of matter quantity under different land-use patterns can reveal the potential ecological vulnerability of HRB through a quantitative perspective and formulate targeted ecological restoration projects, such as returning farmland to forests and grasslands, wind prevention and desertification control, etc. It has opened up new horizons for improving the ecological environment of the Hexi Corridor and building an ecological security barrier in western China. 


\subsection{Grassland Protection and the Healthy Development of Animal Husbandry}

Grassland is the basic resource and condition for human survival, which has important ecological functions such as water conservation, climate regulation, erosion control, nutrient cycling, and so on $[45,46]$. It plays a key role in global change, global cycle, and ecosystem function [47]. Privatization and sedentarization, small mammals, climate change, harsh environments, fragile soils, and overgrazing can all lead to grassland degradation [48]. Shandan County in the middle reaches and Ejina in the lower reaches are vigorously developing grassland protection and vegetation restoration, and their carrying capacity has been significantly improved, which shows that the development of artificial forest and grassland is constantly making up for the damage of natural vegetation, and a series of artificial ecological environment protection and construction measures in the basin have achieved remarkable results $[49,50]$. However, the overload of animal husbandry in other counties and cities has further exacerbated the desertification of grassland, especially in the upper Qilian Mountains [51].

\subsection{Limitation and Innovation}

Due to the limitation of the subject's knowledge and the availability of data, there is no specific accurate accounting model for the proportion of livestock reduction and ecological compensation of different types of grassland cover in the research process, which can only be estimated based on the empirical value of Zhang's research [27]. Therefore, the specific livestock capacity obtained from the research and the analysis is an approximate value, but it directly reflects the dynamic adjustment process of the grassland capacity and livestock amount of the study area. At the same time, the setting of parameters in the calculation of WESs is limited to a static estimation. The assessment system for inter-annual changes and spatial differences needs to be further improved, to further clarify the value of the ecosystem service of HRB.

The biggest innovation of this paper is that it quantitatively depicts the spatial and temporal distribution pattern of water yield, soil retention and erosion, and nitrogen and phosphorus export in HRB through the InVEST model. Under this ecological constraint, RS and GIS are used to quantitatively depict the carrying capacity by combining grassland coverage, natural reserve, water source, soil erosion, slope, etc., to give the amount of livestock in different areas, and to accurately control the ecological protection and construction goals of the basin in different areas, so as to protect the ecosystem and regional economic construction and provide a scientific basis to coordinate development in HRB.

\section{Conclusions}

The upper reaches are dominated by forest ecosystems, and the middle reaches are mainly grassland ecosystems, but the number of grasslands decreased sharply, and the number of bare lands increased significantly. However, the lower reaches are just the opposite: the grasslands have increased obviously, and the bare land has decreased significantly. At the same time, land-use types are shifted frequently, with large spatial differences. In particular, bare land and grassland are frequently transferred, and grassland is transferred from the middle reaches to the lower reaches. Due to the development of animal husbandry, high-covered grasslands are gradually changing to middle-covered and low-covered grasslands. The change of WESs is mainly manifested in the decrease of the water yield in the middle reaches, while the soil in the middle and lower reaches is declining, soil erosion is intensified, nitrogen and phosphorus export is mainly concentrated in the upper and middle reaches, and the pollution is further increasing. The resulting ecological vulnerability cannot be ignored. In addition, the carrying capacity has decreased in the upper reaches, but Shandan and Zhangye cities, in the middle reaches, have been increased, and other areas are decreasing sharply. Ejina is increasing, and Jinta County is decreasing in the lower reaches. Besides, the oasis is mainly concentrated in the middle reaches of the basin, which is also a place with intensive human activities, and the contradiction between grassland supply and demand for animal husbandry is more prominent. 
In this study, the determination of the carrying capacity was achieved mainly through five aspects, namely, the grassland distribution, nature reserves, water sources, soil erosion, and slope. Therefore, the weak links in these five aspects can be accurately controlled. In the future, we should strengthen the research in the following ways: first, by strengthening the protection of high-coverage grasslands to prevent them from being transformed into low- and medium-coverage grasslands, reducing grazing in the medium- and low-coverage areas, and strengthening grassland vegetation restoration; second, the experimental areas and buffer zones of nature reserves are strictly controlled; it is strictly prohibited to damage the nature reserve; third, for the water source areas, the management scope shall be divided according to the region, the responsibilities shall be clarified, and the discharge of human wastewater and miscellaneous waste shall be strictly controlled; fourth, by strengthening the protection of soil erosion and returning targeted forests and grasses to areas with severe erosion; fifth, we should strengthen the orderly management of mountain slopes, maintain the ecological balance, and curb the expansion of the northern desert areas. Therefore, according to the carrying capacity of each county and city, reasonable livestock without overloading, a precise control quantity of the animal husbandry, and the coordination of the relationship between the economy and the natural ecological environment system are the fundamental ways to promote the development of animal husbandry and ensure the safety of the watershed ecosystem.

Supplementary Materials: The following are available online at https://www.mdpi.com/article/ 10.3390/w13192658/s1, Figure S1: Spatial distribution in the Heihe River Basin of (a) precipitation; (b) top solar atmospheric radiation; (c) temperature difference (TD) between the mean maximum temperature and the mean minimum temperature; (d) potential evapotranspiration. Figure S2: Spatial distribution in the Heihe River Basin (a) nature reserve; (b) water source distance in 2000; (c) water source distance in 2018; (d) the suitable area for water source and not in the nature reserve in 2000; (e) the suitable area for water source and not in the nature reserve in 2018. Figure S3: Spatial distribution in the Heihe River Basin (a) slope; (b) grassland area in 2000; (c) grassland area in 2018; (d) erosion area in 2000; (e) erosion area in 2018. Table S1: LULC class definitions from the system of remote sensing investigation and assessment of the 18-year change in ecological environments in China (2000-2018) used in the maps for HRB (2000 and 2018). Table S2: Data requirements for the InVEST model (Water yield model $=$ WY; Nutrient delivery ratio model $=$ NDR; Sediment delivery ratio model $=$ SDR). Table S3: Key parameters used in the present study. Table S4: Critical parameter settings in the biophysical table. Table S5: The area changes of different reaches in the Heihe River Basin in 2000 and 2018. Table S6: Soil erosion transition matrix of the Heihe River Basin from 2000 to 2018 (unit:km²). Table S7: Suitable graze area and graze capacity in 2000 and 2018.

Author Contributions: R.L.: writing—original draft preparation, writing—review \& editing, data curation. S.Y.: writing—original draft preparation, writing—review \& editing, data curation. Y.Z: conceptualization, writing-review \& editing, methodology, software. P.G.: conceptualization, methodology. T.Z.: conceptualization, methodology. R.L. and S.Y. contributed equally to this paper. Therefore, R.L. and S.Y. are all the first authors of this article. All authors have read and agreed to the published version of the manuscript.

Funding: This research was supported by the Fundamental Research Funds for the Central Universities (Grant No. B200203167) and the Postgraduate Research \& Practice Innovation Program of Jiangsu Province (Grant No. KYCX20_0509).

Institutional Review Board Statement: Not applicable.

Informed Consent Statement: Not applicable.

Acknowledgments: We thank editors and reviewers for helpful conversations.

Conflicts of Interest: The authors declare no conflict of interest. 


\section{References}

1. Sannigrahi, S.; Zhang, Q.; Pilla, F.; Joshi, P.K.; Basu, B.; Keesstra, S.; Roy, P.S.; Wang, Y.; Sutton, P.C.; Chakraborti, S.; et al. Responses of ecosystem services to natural and anthropogenic forcings: A spatial regression based assessment in the world's largest mangrove ecosystem. Sci. Total Environ. 2020, 715, 137004. [CrossRef]

2. Zommers, Z.; Wrathall, D.; van der Geest, K. Loss and Damage to Ecosystem Services. Available online: http:/ / collections.unu. edu/view/UNU:2860 (accessed on 22 December 2014).

3. Zhang, L.X.; Fan, J.W.; Zhou, D.C.; Zhang, H.Y. Ecological Protection and Restoration ProgramReduced Grazing Pressure in the Three-River Headwaters Region, China. Rangel. Ecol. Manag. 2017, 70, 540-548. [CrossRef]

4. Bai, Y.; Jiang, B.; Alatalo, J.M.; Zhuang, C.; Wang, X.; Cui, L.; Xu, W. Impacts of land management on ecosystem service delivery in the Baiyangdian river basin. Environ. Earth Sci. 2016, 75, 258. [CrossRef]

5. Peters, M.K.; Hemp, A.; Appelhans, T.; Becker, J.N.; Behler, C.; Classen, A.; Detsch, F.; Ensslin, A.; Ferger, S.W.; Frederiksen, S.B. Climate-land-use interactions shape tropical mountain biodiversity and ecosystem functions. Nature 2019, 568, 88-92. [CrossRef] [PubMed]

6. Mastrorilli, M.; Rana, G.; Verdiani, G.; Tedeschi, G.; Fumai, A.; Russo, G. Economic Evaluation of Hydrological Ecosystem Services in Mediterranean River Basins Applied to a Case Study in Southern Italy. Water 2018, 10, 16. [CrossRef]

7. Aneseyee, A.B.; Soromessa, T.; Elias, E. The effect of land use/land cover changes on ecosystem services valuation of Winike watershed, Omo Gibe basin, Ethiopia. Hum. Ecol. Risk Assess. Int. J. 2020, 26, 2608-2627. [CrossRef]

8. Lafuite, A.S.; Denise, G.; Loreau, M. Sustainable Land-use Management Under Biodiversity Lag Effects. Ecol. Econ. 2018, 154, 272-281. [CrossRef] [PubMed]

9. Alves, L.A.; Denardin, L.G.D.; Martins, A.P.; Anghinoni, I.; Carvalho, P.C.D.; Tiecher, T. Soil acidification and P, K, Ca and $\mathrm{Mg}$ budget as affected by sheep grazing and crop rotation in a long-term integrated crop-livestock system in southern Brazil. Geoderma 2019, 351, 197-208. [CrossRef]

10. Pittarello, M.; Probo, M.; Perotti, E.; Lonatii, M.; Lombardii, G.; Ravetto Enri, S. Grazing Management Plans improve pasture selection by cattle and forage quality in sub-alpine and alpine grasslands. J Mt. Sci. 2019, 16, 2126-2135. [CrossRef]

11. Godde, C.; Dizyee, K.; Ash, A.; Thornton, P.; Sloat, L.; Roura, E.; Henderson, B.; Herrero, M. Climate change and variability impacts on grazing herds: Insights from a system dynamics approach for semi-arid Australian rangelands. Glob. Chang. Biol. 2019, 25, 3091-3109. [CrossRef]

12. You, N.; Meng, J.; Zhu, L. Sensitivity and resilience of ecosystems to climate variability in the semi-arid to hyper-arid areas of Northern China: A case study in the Heihe River Basin. Ecol. Res. 2017, 33, 161-174. [CrossRef]

13. Schirpke, U.; Kohler, M.; Leitinger, G.; Fontana, V.; Tasser, E.; Tappeiner, U. Future impacts of changing land-use and climate on ecosystem services of mountain grassland and their resilience. Ecosyst. Serv. 2017, 26, 79-94. [CrossRef] [PubMed]

14. Zhao, M.; He, Z. Evaluation of the Effects of Land Cover Change on Ecosystem Service Values in the Upper Reaches of the Heihe River Basin, Northwestern China. Sustainability 2018, 10, 4700. [CrossRef]

15. Zhang, J.P.; Zhang, L.B.; Liu, X.N.; Qiao, Q. Research on Sustainable Development in an Alpine Pastoral Area Based on Equilibrium Analysis Between the Grassland Yield, Livestock Carrying Capacity, and Animal Husbandry Population. Sustainability 2019, 11, 4659. [CrossRef]

16. Yu, L.; Zhou, L.; Liu, W.; Zhou, H.K. Using Remote Sensing and GIS Technologies to Estimate Grass Yield and Livestock Carrying Capacity of Alpine Grasslands in Golog Prefecture, China. Pedosphere 2010, 20, 342-351. [CrossRef]

17. Yang, S.; Bai, Y.; Alatalo, J.M.; Wang, H.; Jiang, B.; Liu, G.; Chen, J. Spatio-temporal changes in water-related ecosystem services provision and trade-offs with food production. J. Clean. Prod. 2021, 286, 125316. [CrossRef]

18. Sodango, T.H.; Sha, J.; Li, X.; Noszczyk, T.; Shang, J.; Aneseyee, A.B.; Bao, Z. Modeling the Spatial Dynamics of Soil Organic Carbon Using Remotely-Sensed Predictors in Fuzhou City, China. Remote Sens. 2021, 13, 1682. [CrossRef]

19. Meng, F.; Guo, J.; Guo, Z.; Lee, J.C.; Liu, G.; Wang, N. Urban ecological transition: The practice of ecological civilization construction in China. Sci. Total Environ. 2021, 755, 142633. [CrossRef]

20. Meng, J.; Wu, X.; Li, Z. Land use and land cover changes in Heihe River Basin during the period of 1988-2000. Acta Sci. Nat. Univ. Pekin. 2004, 40, 922-929.

21. Hu, X.; Lu, L.; Li, X.; Wang, J.; Guo, M. Land Use/Cover Change in the Middle Reaches of the Heihe River Basin over 2000-2011 and Its Implications for Sustainable Water Resource Management. PLoS ONE 2015, 10, e0128960. [CrossRef]

22. Na, L.; Tai-bao, Y. Research on LUCC in middle reaches of Heihe River Basin after water redistribution. J. Desert Res. 2008, 28, 223-226.

23. Xiao, S.; Xiao, H. The impact of human activity on the water environment of Heihe water basin in last century. J. Arid Land Resour. Environ. 2004, 18, 57-62.

24. Li, X.; Lu, L.; Cheng, G.; Xiao, H. Quantifying landscape structure of the Heihe River Basin, north-west China using FRAGSTATS. J. Arid Environ. 2001, 48, 521-535. [CrossRef]

25. Lu, L.; Li, X.; Cheng, G. Landscape evolution in the middle Heihe River Basin of north-west China during the last decade. J. Arid Environ. 2003, 53, 395-408. [CrossRef]

26. Wang, J.; Meng, J.-j. Characteristics and tendencies of annual runoff variations in the Heihe River Basin during the past 60 years. Sci. Geogr. Sin. 2008, 28, 88 . 
27. Zhang, H.; Shen, W.; Wang, Y.; Zou, C. Study on grassland grazing capacity in the Heihe River Basin. J. Nat. Resour. 2005, 20, 514-520.

28. Cheng, G.; Li, X.; Zhao, W.; Xu, Z.; Feng, Q.; Xiao, S.; Xiao, H. Integrated study of the water-ecosystem-economy in the Heihe River Basin. Natl. Sci. Rev. 2014, 1, 413-428. [CrossRef]

29. Bhagabati, N.K.; Ricketts, T.; Sulistyawan, T.B.S.; Conte, M.; Ennaanay, D.; Hadian, O.; McKenzie, E.; Olwero, N.; Rosenthal, A.; Tallis, H. Ecosystem services reinforce Sumatran tiger conservation in land use plans. Biol. Conserv. 2014, 169, 147-156. [CrossRef]

30. Terrado, M.; Acuña, V.; Ennaanay, D.; Tallis, H.; Sabater, S. Impact of climate extremes on hydrological ecosystem services in a heavily humanized Mediterranean basin. Ecol. Indic. 2014, 37, 199-209. [CrossRef]

31. Bai, Y.; Ochuodho, T.O.; Yang, J. Impact of land use and climate change on water-related ecosystem services in Kentucky, USA. Ecol. Indic. 2019, 102, 51-64. [CrossRef]

32. Berta Aneseyee, A.; Noszczyk, T.; Soromessa, T.; Elias, E. The InVEST habitat quality model associated with land use/cover changes: A qualitative case study of the Winike Watershed in the Omo-Gibe Basin, Southwest Ethiopia. Remote Sens. 2020, 12, 1103. [CrossRef]

33. Butsic, V.; Shapero, M.; Moanga, D.; Larson, S. Using InVEST to assess ecosystem services on conserved properties in Sonoma County, CAYY. Calif. Agric. 2017, 71, 81-89. [CrossRef]

34. Nelson, E.; Mendoza, G.; Regetz, J.; Polasky, S.; Tallis, H.; Cameron, D.R.; Chan, K.M.A.; Daily, G.C.; Goldstein, J.; Kareiva, P.M.; et al. Modeling multiple ecosystem services, biodiversity conservation, commodity production, and tradeoffs at landscape scales. Front. Ecol. Environ. 2009, 7, 4-11. [CrossRef]

35. Liao, J.; Wang, T.; Xue, X. Oasis evolution in the Heihe River Basin during 1956-2010. J. Desert Res. 2012, 32, $1426-1441$.

36. Weifeng, Q.; Yehua, S.; Bin, F.; Yahua, W. Land use change information mining in highly urbanized area based on transfer matrix: A case study of Suzhou, Jiangsu Province. Geogr. Res. 2013, 32, 1497-1507.

37. Liu, R.; Zhu, D. Methods for detecting land use changes based on the land use transition matrix. Resour. Sci. 2010, 32, 1544-1550.

38. Zhang, L.; Dawes, W.R.; Walker, G.R. Response of mean annual evapotranspiration to vegetation changes at catchment scale. Water Resour. Res. 2001, 37, 701-708. [CrossRef]

39. ZHAO, W.; SHEN, W.; LIU, B.; LIN, N.; WANG, T. Carrying capacity of grasslands and its spatiotemporal change in Tibet, China. Chin. Sci. Bull. 2015, 60, 2014-2028.

40. Holechek, J.L.; Pieper, R.D.; Herbel, C.H. Range Management: Principles and Practices, 2nd ed.; Prentice-Hall: Hoboken, NJ, USA, 1995; ISBN 01-317-44844.

41. García-Ruiz, J.M. The effects of land uses on soil erosion in Spain: A review. Catena 2010, 81, 1-11. [CrossRef]

42. Wang, B.; Zhang, G.h.; Shi, Y.y.; Zhang, X.; Ren, Z.p.; Zhu, L.j. Effect of natural restoration time of abandoned farmland on soil detachment by overland flow in the Loess Plateau of China. Earth Surf. Process. Landf. 2013, 38, 1725-1734. [CrossRef]

43. Dowd, B.M.; Press, D.; Los Huertos, M. Agricultural nonpoint source water pollution policy: The case of California's Central Coast. Agric. Ecosyst. Environ. 2008, 128, 151-161. [CrossRef]

44. Parris, K. Impact of agriculture on water pollution in OECD countries: Recent trends and future prospects. Int. J. Water Resour. Dev. 2011, 27, 33-52. [CrossRef]

45. Dai, G.; Ulgiati, S.; Zhang, Y.; Yu, B.; Kang, M.; Jin, Y.; Dong, X.; Zhang, X. The false promises of coal exploitation: How mining affects herdsmen well-being in the grassland ecosystems of Inner Mongolia. Energy Policy 2014, 67, 146-153. [CrossRef]

46. Gunaratne, A.; Gunatilleke, C.; Gunatilleke, I.; Madawala, H.; Burslem, D. Overcoming ecological barriers to tropical lower montane forest succession on anthropogenic grasslands: Synthesis and future prospects. For. Ecol. Manag. 2014, 329, 340-350. [CrossRef]

47. Cleland, E.E.; Chiariello, N.R.; Loarie, S.R.; Mooney, H.A.; Field, C.B. Diverse responses of phenology to global changes in a grassland ecosystem. Proc. Natl. Acad. Sci. USA 2006, 103, 13740-13744. [CrossRef] [PubMed]

48. Cao, J.; Adamowski, J.F.; Deo, R.C.; Xu, X.; Gong, Y.; Feng, Q. Grassland Degradation on the Qinghai-Tibetan Plateau: Reevaluation of Causative Factors. Rangel. Ecol. Manag. 2019, 72, 988-995. [CrossRef]

49. $\mathrm{Hu}, \mathrm{C}$. Present situation, problem analysis and Countermeasures of grass and livestock industry development and grassland protection and utilization in Shandan County. Gansu Anim. Husb. Vet. 2015, 45, 68-70.

50. Hao, P. Research on Social Evaluation of Turning the Cultivated Land into Forests or Grasslands Project in Heihe River BasinTake Zhangye Prefecture in Gansu Province as an Example. Res. Soil Water Conserv. 2006, 13, $204-207$.

51. LI, Q.-S.; Zhao, W.-Z.; MA, C.-C. Theory and application of forage and livestock coupling for mountainous-oasis-desert country in the Heihe River basin-Study of the Linze demonstration area in the middle reaches of the Heihe River basin for example. Acta Pratacultural Sci. 2004, 4, 13-20. 